\title{
CRITÉRIOS USADOS NA DEFINIÇÃO DE ÁREAS DE INFLUÊNCIAS, IMPACTOS E PROGRAMAS AMBIENTAIS EM ESTUDOS DE IMPACTO AMBIENTAL DE USINAS HIDRELÉTRICAS BRASILEIRAS
}

\author{
CRITERIA APPLIED IN THE DEFINITION OF INFLUENCE AREAS, IMPACTS AND \\ PROGRAMMES IN ENVIRONMENTAL IMPACT STUDIES OF BRAZILIAN HYDROELECTRIC \\ POWER PLANTS
}

\author{
Dayane Nayara CARVALHO ${ }^{1}$, Milena Rodrigues BONIOLO ${ }^{1}$, Rafael Gonçalves \\ SANTOS $^{1}$, Ludmila Vianna BATISTA ${ }^{1}$, André Aparecido MALAVAZZI ${ }^{2}$, Fábio Augusto \\ Gomes Vieira REIS ${ }^{1}$, Lucilia do Carmo GIORDANO ${ }^{3}$ \\ ${ }^{1}$ Programa de Pós Graduação em Geociências e Meio Ambiente - Instituto de Geociências e Ciências Exatas, Univesidade Estadual \\ Paulista. Rio Claro, SP. Email: dadaybio@gmail.com; milenaboniolo@usp.br; rafaelgoncalves@campus.ul.pt; \\ ludvbatista@yahoo.com.br; fabioreis@rc.unesp.br \\ ${ }^{2}$ Programa de Pós Graduação em Geografia - Instituto de Geociências e Ciências Exatas, Univ. Estadual Paulista. Rio Claro, SP. \\ Email: depgeog@rc.unesp.br \\ ${ }^{3}$ Bolsista Fundunesp - Instituto de Geociências e Ciências Exatas, Univ. Estadual Paulista. Rio Claro, SP. \\ Email: lcg@ecogeologia.com.br

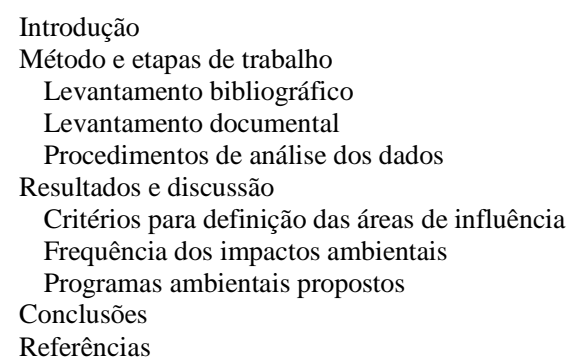

RESUMO - A necessidade de ampliação da oferta de energia para o crescimento e desenvolvimento da economia é uma realidade crescente do país. Porém, a expansão da energia proveniente de usinas hidrelétricas é um tema polêmico em relação às suas potencialidades, impactos gerados e metodologias utilizadas em seu licenciamento. Assim, este trabalho procurou, por meio de revisão bibliográfica e análise documental, formular uma síntese de forma a abranger as principais similaridades e diferenças nos Estudos de Impacto Ambiental de nove diferentes empreendimentos hidroelétricos. Verificou-se que os critérios utilizados para definição das áreas de influência foram similares em todos os estudos analisados, especialmente, entre os meios físico e biótico. Também foi observada a alta quantidade de impactos durante a fase de implantação e operação do empreendimento, indicando a necessidade de maior atenção em relação aos programas e medidas ambientais adotados nessas fases. A diferença na frequência relatada de alguns impactos reflete a relação que estes têm com características locais da região. Também se verificou a falta de padronização para definição das áreas de influência e dos métodos de avaliação de impactos analisados. Portanto, esse artigo contribui com a discussão dos critérios adotados na elaboração dos Estudos de Impacto Ambiental de Hidrelétricas.

Palavras-chave: usinas hidrelétricas, áreas de influência, estudos de impacto ambiental, EIA.

\begin{abstract}
The need to expand the energy supply in order to provide economic growth and development is a growing reality in Brazil. However, the expansion of energy generated from hydroelectric power plants is controversial due to its potentialities, generated impacts and methodologies applied in its licensing. Thus, this study sought, through bibliographical review and documentary analysis, to formulate a synthesis covering the main similarities and differences in Environmental Impact Studies of nine different hydroelectric power plants projects. It was verified that the criteria applied in the definition of influence areas were similar in all studies analysed, especially between the physical and biotic environments. It was also observed high number of impacts during the implementation and operation phase of these projects, indicating the need for greater attention to environmental programmes and the measures adopted in these phases. The difference in reported frequency of some impacts reflects the relationship they have with local features of the region. It was also verified lack of standardisation in the definition of influence areas and evaluation methods of the impacts analysed. Therefore, this article contributes to the discussion of the criteria adopted in the elaboration of Environmental Impact Studies of hydroelectric power plants.
\end{abstract}

Keywords: hydroelectric power plant, influence areas, environmental impact studies, EIA.

\section{INTRODUÇÃO}

A partir da década de 1950, o processo de industrialização do país impulsionou o incremento das fontes de energia necessário aos novos projetos em desenvolvimento. Desde então, os modelos de produção e consumo exigem cada vez mais dos recursos naturais, em especial dos energéticos (Bortoleto, 2001). Na matriz energética brasileira destaca-se como principal fonte, a hidrelétrica, que conta hoje com um total de 1.064 usinas produzindo 84.800.441 kW (ANEEL, 2013), o que corresponde a mais de $75 \%$ de toda a energia 
gerada no país (BRASIL, 2012). Há previsões de que sejam implantadas, até 2015, mais 494 usinas hidrelétricas em todo o país (Oliveira \& Zhouri, 2007) e de que o consumo per capita aumente 52\% de 2011 a 2021, segundo dados do Plano Decenal de Expansão de Energia (BRASIL, 2012).

As construções da barragem e estrutura da usina modificam o meio e a comunidade em seu entorno. Até os anos de 1980, não existia no Brasil uma preocupação em realação a conservação do meio socioambiental frente aos grandes projetos de engenharia (Colito, 2000). Porém, com a implementação da Política Nacional de Meio Ambiente, pela Lei Federal $\mathrm{n}^{0}$ 6.938, de 31 de agosto de 1981, e da Resolução 001/86 do Conselho Nacional de Meio Ambiente - CONAMA, a conciliação do desenvolvimento com a preservação do meio natural passou a ser peça chave para a realização de novos empreendimentos (BRASIL, 1981; 1986). Toda nova instalação ou atividade deve ser licenciada pelos órgãos ambientais competentes e quando esses novos empreendimentos são causadores de modificações potenciais significativas nos meios físico, biótico e social, o licenciamento deve ser condicionado a apresentação de um Estudo de Impactos Ambientais (EIA) (Sánchez, 2006).

O EIA refere-se a um estudo ambiental detalhado requerido nas etapas de licenciamento ambiental prévio, sendo composto basicamente, pelo diagnóstico ambiental da área, no qual são consideradas as características da região onde se pretende implantar o empreendimento, a identificação e avaliação dos impactos reais e potenciais que podem surgir durante as várias fases do projeto, as melhores alternativas locacionais frente a esses impactos, e os programas e medidas ambientais que devem ser adotados para minimizar, mitigar, controlar ou compensar tais modificações negativas e potencializar as positivas (Sánchez, 2006; INEA, 2008).

Todo impacto deve ser caracterizado de acordo com sua natureza (se ocorre no meio físico, biótico ou socioeconômico), considerando também os conceitos de áreas de influência (AI), que delimitam a abrangência dos impactos gerados pelo empreendimento (CEPEMAR, 2004). A definição da área de influência é de suma importância para o desenvolvimento de qualquer tipo de estudo ambiental, pois, refere-se à área onde serão sentidos os efeitos dos impactos positivos e negativos do empreendimento.

O Inciso III do artigo $5^{\circ}$ da Resolução CONAMA n. 001/86 estabelece a seguinte diretriz na elaboração de EIA/RIMA: "Definir os limites da área geográfica a ser direta ou indiretamente afetada pelos impactos, denominada área de influência do projeto, considerando, em todos os casos, a bacia hidrográfica na qual se localiza” (BRASIL, 1986). Portanto, a área de influência de um empreendimento compreende a extensão geográfica a ser afetada direta e indiretamente pelos impactos gerados nas fases de planejamento, implantação, operação e desativação (quando for o caso) do mesmo, definindo a bacia hidrográfica como uma fundamental unidade territorial da avaliação ambiental.

Dessa forma, as áreas de influência indicam os limites geográficos representativos dos impactos ambientais identificados, sendo comumente divididas em:

- Área Diretamente Afetada (ADA): área na qual o empreendimento será instalado, incluindo tanto os locais efetivamente afetados pelos projetos e obras como as estruturas do empreendimento, envolvendo, ainda, estruturas complementares como: canteiros de obras, acessos, estações de tratamento de efluentes, jazidas de solo e rocha e depósitos de rejeito e resíduos, sendo assim, a área que sofrerá impactos ambientais mais significativos previstos durante as diferentes fases do empreendimento. No caso de hidroelétricas a ADA abrange, além dos locais citados anteriormente, o reservatório, a barragem, a casa de força, o vertedouro e a Área de Preservação Permanente (APPs) que envolve o reservatório.

- Área de Influência Direta (AID): engloba a Área Diretamente Afetada e é o local em que os impactos gerados afetam diretamente o meio ambiente e a sociedade, principalmente, por impactos diretos ou de primeira ordem, sendo representada, em geral, pela área adjacente ao empreendimento e pela bacia hidrográfica em que este se localiza, nos casos dos meios físico e biótico, e pelas propriedades rurais e 
comunidades afetadas no entorno no caso do meio socioeconômico.

- Área de Influência Indireta (AII): corresponde à região em que os impactos serão observados de forma indireta ou afetados por impactos de segunda ordem ou superior, ocasionados pelo efeito cumulativo e sucessivo que as modificações provocam no meio. Quando elas são descritas para o meio socioeconômico, geralmente são representadas pela área total dos municípios afetados pelo empreendimento ou por uma bacia hidrográfica de ordem hierárquica superior no caso dos meios físico e biótico.

Além destas, outras classificações são usadas em alguns estudos ambientais, como por exemplo, a Área de Abrangência Regional (AAR), Área de Influência Remota (AIR) ou Área de Influência Estratégica (AIE), sendo estabelecida como a macro região onde poderão ser encontrados impactos cumulativos decorrentes de outros empreendimentos existentes na região, caracterizando o estudo em um contexto regional, contudo, não são conceitos consagrados e amplamente adotados pelos estudos ambientais e pela bibliografia especializada.

Nesse contexto, a área de influência é considerada de modo diferenciado de acordo com o meio em que está sendo analisado e pelo aspecto ou fator ambiental. O meio físico e biótico é tratado por muitos estudos de forma conjunta, sendo considerados como meio natural, principalmente, devido às relações intrínsecas que esses meios guardam na formação de ecossistemas e dos processos naturais. Já o meio socioeconômico ou antrópico apresenta, na maioria dos casos, áreas de influência diferentes, já que é levado em conta as interferências ocasionadas a toda população envolvida.

É importante diferenciar também o conceito de "áreas de influência” de "área de estudo". A área de estudo é definida como a região onde serão realizados os estudos de diagnóstico ambiental que subsidiarão a Avaliação de Impactos Ambientais (AIA). É na área de estudo onde são desenvolvidos os estudos para caracterização da situação atual dos diferentes fatores ambientais em cada meio. Já a área de influência é definida somente após a avaliação dos impactos, tendo sua abrangência determinada de acordo com o poder de transformação dos impactos identificados nos meios físico, biótico e social (Sánchez, 2006).

Nesse contexto, Sanchez (2006, p. 285) ressalta que "somente depois da previsão de impactos que se pode tirar alguma conclusão sobre a área de influência do projeto", afirmando ainda, que "se o projeto for implantado, é o monitoramento ambiental que estabelecerá sua real área de influência, desde que o programa de monitoramento seja capaz de discernir as modificações causadas por ele daquelas que têm outras causas”.

Portanto, antes de se definir as áreas de influência do empreendimento, ainda na etapa de planejamento do EIA, é necessário estabelecer as áreas onde os estudos e levantamentos serão desenvolvidos e executados para realizar o diagnóstico ambiental de cada meio, que são denominadas de Áreas de Estudo.

Sanchez (2006) define área de estudo como “área geográfica onde serão realizados os estudos de base, área que será objeto de coleta de dados primários ou secundários. É muito comum confundir área de estudo com área de influência”. Já para área de influência o Autor apresenta o seguinte conceito: “a área cuja qualidade ambiental sofrerá modificações direta ou indiretamente decorrentes do empreendimento”. O autor ressalta, ainda, que “ por sua vez, a área de estudo é simplesmente aquela em que serão coletadas informações a fim de realizar o diagnóstico ambiental...”

Entretanto, é importante ressaltar que atualmente não existe no Brasil uma padronização, seja na legislação seja em estudos técnico-científicos (Santos, 2004; Sanchez, 2006) para definição de áreas de estudo ou mesmo de áreas de influência, com exceção da Resolução CONAMA n. 001/1986, que estabelece a bacia hidrográfica como a unidade de análise para definição de área de influência, conforme citado anteriormente.

Tanto que Santos (2004) afirma sobre esse assunto que “a questão de delimitação de área de influência ainda permanece indefinida quanto a critérios, metodologia e escalas apropriadas para estudo de diversos tipos de interferência modificadoras do ambiente”. Atualmente, os Termos de Referência elaborados pelos órgãos licenciadores 
evoluíram bastante na exigência de estabelecer os critérios para definição das áreas de influência, contudo, ainda, não existe no país uma padronização de termos e critérios básicos a serem usados pela equipe técnica.

Nos EIA/RIMAs devem ser apresentados os critérios que foram utilizados para a delimitação das áreas de influência do projeto. Porém, a dificuldade em se estabelecer essas áreas e a deficiência em legislações que unifiquem e orientem os empreendedores faz com que muitos trabalhos não especifiquem esses critérios de forma clara, o que gera dúvidas e incertezas na avaliação do estudo.

Ainda sobre esse assunto, Santos (2004) afirma que "para definir a área de estudo, devese partir de considerações sobre a complexidade local, a abrangência e o núcleo dos principais problemas regionais, as escalas necessárias para avaliar as questões ambientais e o tamanho das unidades territoriais envolvidas. Porém, independentemente desses fatores de influência sobre o meio, é comum que a equipe planejadora defina a bacia hidrográfica - um espaço desenhado pela natureza - como unidade de trabalho".

Santos (2004) destaca também que "o critério de bacia hidrográfica é comumente usado porque constitui um sistema natural bem delimitado no espaço, composto por um conjunto de terras topograficamente drenadas por um curso d'água e seu afluentes, onde as interações, pelo menos físicas, são integradas e, assim, mais facilmente interpretadas. Esta unidade territorial é entendida como uma caixa preta, onde os fenômenos e interações podem ser interpretados, a priori, pelo input e output". A autora enfatiza que "a seleção da bacia hidrográfica como área de trabalho para avaliação ambiental está assumida em muitos estudos acadêmicos, planejamentos oficiais”

Além disso, Santos (2004) também apresenta as ponderações de quando a bacia hidrográfica não é unidade de análise adequada, afirmando que "quando a bacia hidrográfica torna-se o espaço das funções urbanas ou do campo, a complexidade aumenta, pela diversificação de produtores e consumidores, pelo aumento das relações intrínsecas e pela sua dependência de fontes externas, criando uma malha que, comumente, transcende o território da bacia” Destacando, ainda, que "a unidade natural 'bacia hidrográfica' não contém em seus limites todas relações que se impõe diante das necessidades e dos anseios dos grupos sociais em seu espaço”.

Os tipos de áreas de estudo mais comumente usados em estudos ambientais são: bacia hidrográfica, limite territorial/administrativo, raio de ação, corredor e unidade homogênea (Santos, 2004; Leli et al., 2012).

Outro aspecto fundamental na elaboração de Estudos de Impacto Ambiental refere-se à determinação do grau de significância dos impactos, ou seja, o poder de transformação que cada um deles exerce sobre o meio e a sociedade (Thompson, 1990).

Para cada impacto negativo identificado, deverão ser propostas medidas e programas ambientais que visem sua mitigação, controle e/ou compensação. De forma contrária, os impactos positivos devem ser estimulados e ampliados. São os programas ambientais que nortearão as ações desenvolvidas para proteger o meio ambiente e a comunidade dessas modificações, sendo essenciais nos Estudos de Impacto Ambiental e para a manutenção da qualidade ambiental do ecossistema e da população afetados.

Portanto, o objetivo do presente trabalho é analisar os principais critérios usados para a definição de Áreas de Influência (AI) em Estudos de Impacto Ambiental (EIA) de Usinas Hidrelétricas (UHE), além de identificar as principais semelhanças e diferenças existentes na determinação dos impactos e programas ambientais definidos para esse tipo de empreendimento.

\section{MÉTODO E ETAPAS DE TRABALHO}

Os estudos para desenvolvimento da presente pesquisa consideraram basicamente levantamentos bibliográfico e documental a partir da análise de artigos e trabalhos técnicocientíficos sobre os temas abordados e de Estudos de Impacto Ambiental, disponíveis para consulta pública, de empreendimentos licenciados no Brasil.

Para organização e tabulação dos dados disponíveis no EIAs foram elaborados quadros para cada empreendimento levantado, considerando os critérios para definição de áreas de influência, os impactos ambientais em cada fase do empreendimento (planejamento, instala- 
ção e operação) e os programas ambientais.

Em seguida, foi feita uma análise dos dados coletados considerando os aspectos abordados nos EIAs que eram semelhantes e não representassem somente situações específicas associadas a localização ou especificidade do empreendimento, possibilitando a elaboração de quadros síntese sobre os critérios usuais para definição de áreas de influência e os impactos e programas ambientais comumente identificados em Usinas Hidrelétricas. Nesse contexto, as seguintes etapas de trabalho foram consideradas.

\section{Levantamento Bibliográfico}

Foram definidas palavras-chave de busca que direcionaram o levantamento bibliográfico junto às bases de dados, bibliotecas de dissertações e teses, livros e órgãos ambientais. As expressões utilizadas foram: Usinas Hidrelétricas, Estudos de Impacto Ambiental, Áreas de Influência e Impactos e Programas Ambientais.

O levantamento bibliográfico foi feito em bases de pesquisa confiáveis, como banco de dados bibliográficos Athena da Universidade Estadual Paulista Júlio de Mesquita Filho (UNESP) - Acervo Geral, Biblioteca Digital de Teses e Dissertações da UNESP, Portal de periódicos da Capes e sites oficiais do governo.

Com base nas informações selecionadas foi possível analisar os conceitos e critérios usados para definição de áreas de influência, impactos e programas ambientais em Estudos de Impacto de Ambiental, com ênfase para as Usinas Hidrelétricas.

\section{Levantamento Documental}

A escolha dos empreendimentos, bem como dos Estudos de Impacto Ambiental (EIAs) analisados, fez-se de acordo com critérios previamente estabelecidos, como localização e tamanho das Usinas Hidrelétricas (CHESF, 1993; CNEC ENGENHARIA S/A, 2001, 2004; CEPEMAR, 2004; EPE, 2007, 2008; ECOLOGY BRASIL, 2009, 2011; PROJETEC - PROJETOS TÉCNICOS LTDA; CNEC-ENGENHARIA
S/A, 2009a, 2009b), ano de elaboração dos EIAs e capacidade de operação das usinas, buscando sempre uma ampla diversidade de variáveis. Dessa forma, foram escolhidas as seguintes Usinas Hidrelétricas: Tijuco Alto, Estreito, São Manoel, Teles Pires, Itaocara, Santo Antônio de Jari, Xingó, Urucuí e Cachoeira. Todas elas foram licenciadas pelo Instituto Brasileiro do Meio Ambiente e dos Recursos Naturais Renováveis (IBAMA).

$\mathrm{Na}$ figura 1 encontram-se detalhadas as principais características das Usinas Hidrelétricas como: localização geográfica, potência outorgada e nome dos principais rios relacionados a cada UHE analisadas no trabalho. Foi utilizado o software ArcGis 9.3 e tendo como base um mapa do Brasil foram inseridas as coordenadas UTM de cada uma das usinas hidrelétricas consideradas.

Em cada um desses estudos foram analisados os critérios utilizados na definição das áreas de influência; a escolha dos impactos observados nas fases de planejamento, implantação e operação do empreendimento e os programas ambientais propostos para a mitigação, redução, controle e compensação desses impactos. A partir desses dados foram elaborados quadros para cada empreendimento com as informações coletadas.

\section{Procedimentos de Análise dos Dados}

A partir dos levantamentos bibliográfico e documental, os dados foram agrupados de forma a possibilitar a visualização das principais tendências na classificação das áreas de influência, bem como dos impactos identificados em cada fase dos projetos e obras para Usinas Hidrelétricas.

Em seguida, os dados foram tabulados e organizados para gerar quadros síntese com os aspectos que se repetem na maioria dos estudos e não reflitam especificidades de localização ou do empreendimento, possibilitando, dessa forma, identificar um padrão para elaboração de EIAs de Usinas Hidrelétricas.

\section{RESULTADOS E DISCUSSÃO}

A seguir são apresentados os resultados obtidos ao longo do desenvolvimento do trabalho, considerando os critérios usados nos Estudos de Impacto Ambiental para definição das áreas de influência e os principais impactos e programas ambientais que são relacionados nesses estudos para usinas hidrelétricas.

\section{Critérios para definição das áreas de Influência}

De acordo com os EIAs analisados, foram descritas as principais definições de áreas de influência das UHEs, conforme mostra a figura 2. De acordo com as análises realizadas, todos os nove EIAs utilizaram critérios semelhantes para 
definir a Área de Influência Direta (AID) e Área de Influência Indireta (AII).

Essa semelhança pode ter sido gerada devido a todos estes estudos terem sido licenciados pelo mesmo órgão ambiental, no caso, o IBAMA, que pode condicionar as definições das áreas de influência no Termo de Referência que o empreendedor deve seguir.

Deste total, 77,8\% consideraram nos Estudos de Impacto Ambiental a Área Diretamente Afetada (ADA) e 55,5\% abordaram ainda a Área de Abrangência Regional (AAR). O Impacto Ambiental a Área Diretamente Afetada e a Área de Abrangência Regional vem sendo consideradas apenas recentemente nos estudos ambientais, o que pode explicar a razão de sua ausência em estudos mais antigos, nos quais era mais comum somente definir a AID e AII.

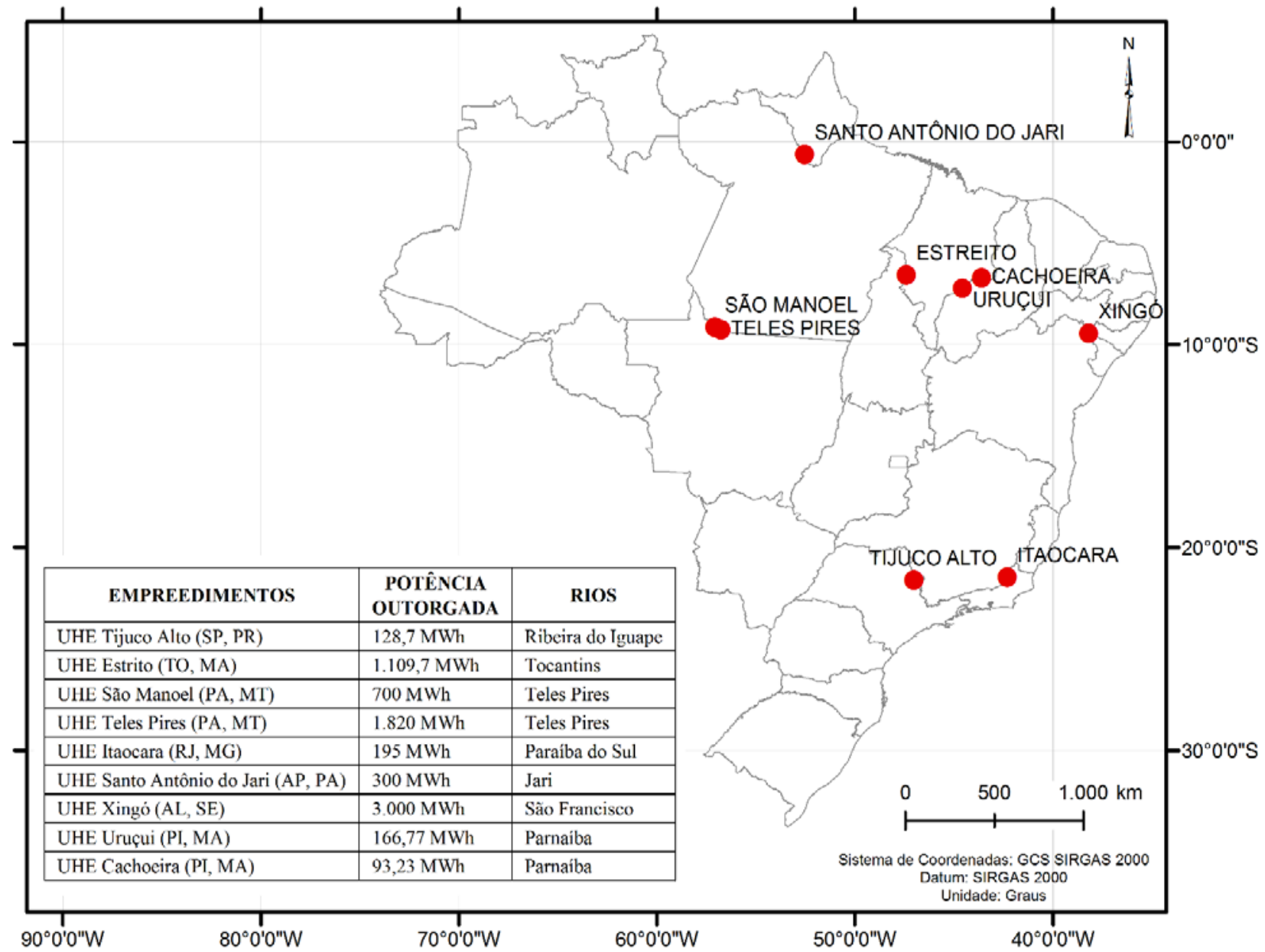

Figura 1 - Localização e características principais da UHE analisadas.

Pode-se verificar, ainda, que para os meios físico e biótico a tendência é usar um mesmo critério para definir as áreas de influência, respeitando, em geral, a bacia hidrográfica ou uma faixa marginal como unidade de análise. A união dos meios físico e biótico nos estudos pode ser explicada pelo fato destes serem meios dependentes e relacionados. A alteração em um ocasiona, na maioria das vezes, em modificações também no outro, sendo, portanto, analisados pela maioria dos estudos de forma conjunta.

Já para o meio socioeconômico, o limite administrativo dos municípios foi usado como critério básico para as avaliações dos impactos ambientais dos empreendimentos. Isso pode ser devido ao fato de que a modificação na estrutura social de parte de uma população afeta, inevitavelmente, todo o município em que esta população está inserida.

Essa classificação do meio socioeconômico é uma tendência, não somente verificada em usinas hidrelétricas, mas seguida como critérios para todo tipo de empreendimento, especialmente, para os locais e regionais, como é o caso de loteamentos, minerações, indústrias, estações de tratamento de esgoto e água, entre outros.

Situação um pouco diferente da verificada em empreendimentos lineares, como dutos, linhas de transmissão, rodovias, que tendem a 
usar faixas marginais ao empreendimento como áreas de influência.

Ressalta-se, ainda, que em nenhum dos estudos analisados foi feita a diferenciação entre área de estudo e área de influência, definindo antes do início do diagnóstico ambiental os limites previstos para as áreas de estudo de cada fator ambiental (geologia, recursos hídricos, clima, geomorfologia, fauna, flora, unidades de conservação, arqueologia, dinâmica populacional, dentre outros) em cada meio analisado (físico, biótico e socioeconômico), e somente após a avaliação de impactos ambientais estabelecidas as áreas de influência.

\begin{tabular}{|c|c|c|c|c|c|}
\hline 㣉 & 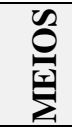 & ADA & AID & AII & AAR \\
\hline \multirow{3}{*}{ 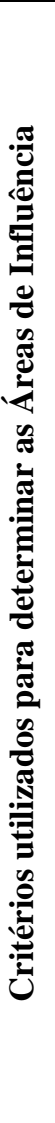 } & 蒙 & $\begin{array}{l}\text { Compreende os } \\
\text { locais da obra: } \\
\text { canteiros de obras, } \\
\text { alojamentos, } \\
\text { acessos, etc. } \\
\text { Engloba ainda a } \\
\text { região que será } \\
\text { alagada e a área de } \\
\text { APP } \\
\end{array}$ & $\begin{array}{c}\text { Compreende além da } \\
\text { área do reservatório, uma } \\
\text { faixa marginal que } \\
\text { variou de } 1 \mathrm{Km} \text { a } 7 \mathrm{Km} \text {. } \\
\text { Foi, portanto, } \\
\text { considerada a região } \\
\text { imediatamente após a } \\
\text { ADA }\end{array}$ & $\begin{array}{l}\text { Compreende a bacia } \\
\text { contribuinte de drenagem do } \\
\text { rio em que será construída a } \\
\text { barragem, levando em conta } \\
\text { todos os seus afluentes, uma } \\
\text { porção a montante e a jusante } \\
\text { da área do reservatório }\end{array}$ & $\begin{array}{l}\text { Engloba toda } \\
\text { a bacia do rio }\end{array}$ \\
\hline & 葛 & $\begin{array}{l}\text { Compreende os } \\
\text { locais da obra: } \\
\text { canteiros de obras, } \\
\text { alojamentos, } \\
\text { acessos, etc. } \\
\text { Engloba ainda a } \\
\text { região que será } \\
\text { alagada e a área de } \\
\text { APP } \\
\end{array}$ & $\begin{array}{c}\text { Compreende além da } \\
\text { área do reservatório, uma } \\
\text { faixa marginal que } \\
\text { variou de } 1 \mathrm{Km} \text { a } 7 \mathrm{Km} \text {. } \\
\text { Foi, portanto, } \\
\text { considerada a região } \\
\text { imediatamente após a } \\
\text { ADA }\end{array}$ & $\begin{array}{l}\text { Compreende a bacia } \\
\text { contribuinte de drenagem do } \\
\text { rio em que será construída a } \\
\text { barragem, levando em conta } \\
\text { todos os seus afluentes, uma } \\
\text { porção a montante e a jusante } \\
\text { da área do reservatório }\end{array}$ & $\begin{array}{l}\text { Engloba toda } \\
\text { a bacia do rio }\end{array}$ \\
\hline & 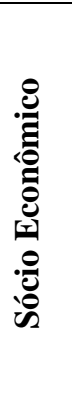 & $\begin{array}{l}\text { Compreende os } \\
\text { locais da obra: } \\
\text { canteiros de obras, } \\
\text { alojamentos, } \\
\text { acessos, etc. } \\
\text { Engloba ainda a } \\
\text { região que será } \\
\text { alagada e a área de } \\
\text { APP }\end{array}$ & $\begin{array}{c}\text { Corresponde aos } \\
\text { municípios e/ou } \\
\text { propriedades rurais que } \\
\text { terão suas terras } \\
\text { diretamente afetadas } \\
\text { pelo reservatório, seja } \\
\text { devido a inundação ou } \\
\text { diminuição da água na } \\
\text { propriedade }\end{array}$ & $\begin{array}{c}\text { Engloba a área total dos } \\
\text { municípios que, mesmo não } \\
\text { tendo suas terras alagadas pela } \\
\text { represa, sofrerão as } \\
\text { consequências indiretas do } \\
\text { empreendimento, como } \\
\text { aumento no fluxo de pessoas, } \\
\text { geração de matérias primas } \\
\text { para a obra, geração de } \\
\text { emprego, etc }\end{array}$ & $\begin{array}{l}\text { Engloba toda } \\
\text { a bacia do rio } \\
\text { e todos os } \\
\text { municípios } \\
\text { afetados direta } \\
\text { ou } \\
\text { indiretamente }\end{array}$ \\
\hline
\end{tabular}

Figura 2 - Resumo das áreas de influência dos EIAs analisados.

Nesses EIAs são estabelecidas somente as áreas de influência, que inclusive não são diferentes em cada fator ambiental e sim diferenciadas pelo meio analisado. Portanto, verificou-se que não há padronização em relação as áreas de influência, como também existe uma confusão em relação aos conceitos e critérios para definição de áreas de estudo e de influência, conforme estabelecem Santos (2004) e Sanchez (2006).

\section{Frequência dos Impactos Ambientais}

A frequência dos impactos ambientais foi avaliada nos Estudos de Impacto Ambiental nas fases de planejamento, implantação e operação. A fase de desativação foi abordada apenas pela Usina Teles Pires, e portanto, não foi considerada neste trabalho, devido à impossibilidade em se efetuar uma análise comparativa com outros estudos.

De acordo com a tabela 1, pode-se observar que na fase de planejamento, a expectativa da população em relação a geração de novos empregos bem como a atração de migrantes, mobilização de segmentos populacionais afetados pelo empreendimento, especulação imobiliária e alterações no uso e ocupação e serviços foram considerados como impactos ambientais em mais de $50 \%$ dos EIAs analisados. Esse resultado mostra serem estes impactos inerentes no planejamento de usinas hidrelétricas, já que se relacionam diretamente com o bem estar da população envolvida.

Já questões relacionadas à redução da confiabilidade da população no empreendi- 
mento, poluição dos recursos hídricos, emissão de gases estufa, redução da biomassa vegetal, queda da qualidade do ar, influência na biota aquática, desestruturação dos laços comunitários, dentre outros, foram impactos descritos em apenas 10\% dos EIAs estudados, considerando a fase de planejamento. Isso porque, nesta fase, ainda são feitas poucas intervenções estruturais no local, em comparação a fase de implantação, por exemplo, o que gera menos impactos no meio.

Pode-se verificar certa incoerência em alguns EIAs no que diz respeito à relação de impactos que normalmente não se referem à fase de planejamento ou não são comumente relatados nela, como, por exemplo, poluição dos recursos hídricos, emissão de gases estufa, redução da biomassa vegetal, queda da qualidade do ar, entre outros. Espera-se que, nessa fase, os impactos normalmente estejam associados à expectativa da população em relação a alguns aspectos específicos ou problemas com questões legais ou incompatibilidade com planos e programas de ordenação territorial ou com áreas indígenas, quilombolas ou unidades de conservação.

Tabela 1- Frequência dos impactos observados na fase de planejamento dos EIAs.

\begin{tabular}{|c|c|}
\hline TIPO DE IMPACTO & $(\%)$ \\
\hline Redução da Confiabilidade do Sistema Elétrico & 11 \\
\hline Emissão de Gases do Efeito Estufa & 11 \\
\hline Redução da Biomassa Vegetal & 11 \\
\hline Queda da Qualidade do Ar & 11 \\
\hline Interferência com a Biota Aquática & 11 \\
\hline Desestruturação dos Laços Comunitários & 11 \\
\hline Expectativa da População Rural e Urbana com Relação ao Empreendimento & 11 \\
\hline Aumento da Pesca e Caça Predatória & 11 \\
\hline Poluição dos Recursos Hídricos por Fontes de Poluição Difusa & 11 \\
\hline Ocorrência de Acidentes de Trabalho e de Doenças Ocupacionais & 11 \\
\hline Redução de Investimentos Públicos e Serviços & 11 \\
\hline Queda na Produção Leiteira & 11 \\
\hline Restrição ao Crescimento Socioeconômico & 22 \\
\hline Alteração da Qualidade de Vida & 22 \\
\hline Conflito entre Empreendedor e População & 22 \\
\hline Pressão na Economia Pesqueira Local & 33 \\
\hline Ocupação das Planícies de Inundação & 33 \\
\hline Alteração do Potencial de Aptidão Agrícola do Solo & 33 \\
\hline Redução da Diversidade da Fauna Terrestre & 33 \\
\hline Alteração da Estrutura da Biota Terrestre & 33 \\
\hline Risco de Atritos com a População & 33 \\
\hline Deslocamento Compulsório de Famílias & 33 \\
\hline Alteração da Qualidade de Vida & 33 \\
\hline Alteração da Qualidade da Água & 44 \\
\hline Deflagração de Processos Erosivos & 44 \\
\hline Aumento da Pressão Antrópica Sobre a Vegetação & 44 \\
\hline Desestruturação da Unidade Produtiva da Família Rural & 44 \\
\hline Especulação Imobiliária: Áreas Urbanas & 44 \\
\hline Redução dos Investimentos nas Propriedades Rurais & 44 \\
\hline Ampliação do Conhecimento Técnico-Científico & 44 \\
\hline Expectativa da População pela Geração de Empregos & 56 \\
\hline Atração de Migrantes & 56 \\
\hline Mobilização de Segmentos Populacionais Afetados pelo Empreendimento & 56 \\
\hline Especulação Imobiliária: Mercado de Terras Rurais & 56 \\
\hline Alterações nos Usos e Ocupação e Serviços Urbanos & 56 \\
\hline
\end{tabular}

Na Tabela 2 são apresentados os impactos ambientais relacionados nos EIAs na fase de implantação. Nota-se que em $100 \%$ dos EIAs avaliados, os processos erosivos, perda de solos, deslizamentos e contaminação por agentes biológicos foram identificados, não importando seu tamanho e potência outorgada, já que os empreendimentos analisados neste trabalho variaram de 93 MWh, como a UHE Cachoeira, até 3.000 MWh, no caso da UHE Xingó. 
Esse resultado mostra que estes impactos são intrínsecos a qualquer instalação de usinas hidrelétricas devido às próprias características de implantação do empreendimento que incluem abertura de estradas, instalação de canteiro de obras, escavações em solo e em rocha, dentre outras interferências.
Já impactos referentes ao aumento da vazão de aquíferos profundos, perda de patrimônio espeleológico dentre outros impactos foram abordados em apenas 10\% dos EIAs em análise. Isso se reflete em parte, pela especificidade de tais impactos, que dependem de características do ambiente para que ocorram.

Tabela 2 - Frequência dos impactos observados na fase de implantação dos EIAs.

\begin{tabular}{|c|c|}
\hline TIPO DE IMPACTO & $\%$ \\
\hline Desestabilização de Fundações e Estruturas Enterradas & 11 \\
\hline Aumento de Vazão de Aquíferos Profundos & 11 \\
\hline Perda de Patrimônio Espeleológico & 11 \\
\hline Estanqueidade do Reservatório & 11 \\
\hline Colonização por Espécies Invasoras de Flora e Fauna & 11 \\
\hline Interrupção do Sistema Viário Regional & 11 \\
\hline Impedimento de Navegação à Jusante da Barragem & 11 \\
\hline Alteração da Qualidade de Vida & 22 \\
\hline Conflito entre Empreendedor e População & 22 \\
\hline Processo de Carstificação & 33 \\
\hline Pressão no Modo de Vida de Comunidades Urbanas e Rurais & 33 \\
\hline Aumento do Índice de Prostituição & 33 \\
\hline Especulação Imobiliária: Áreas Urbanas e Rurais & 33 \\
\hline Interferência nas Economias Urbanas & 33 \\
\hline Produção Agropecuária Cessante & 33 \\
\hline Inundação de Instalações Portuárias & 33 \\
\hline Perda de Pontos de Interesse Paisagístico-Turístico & 33 \\
\hline Pressão na Economia Pesqueira Local & 33 \\
\hline Aumento da Disponibilidade de Águas Subterrâneas & 44 \\
\hline Formação de Áreas Úmidas e Alagadas & 44 \\
\hline Poluição do Aquífero & 44 \\
\hline Proliferação de Macrófitas Aquáticas & 44 \\
\hline Acidentes de Trabalho e Geração de Doenças Ocupacionais & 44 \\
\hline Armazenamento de Resíduos Sólidos & 44 \\
\hline Aumento da Pesca e Caça Predatória, Comercial, Esportiva e de Subsistência & 56 \\
\hline Alteração dos Ambientes Marginais & 56 \\
\hline Destruição do Patrimônio Cênico Natural & 67 \\
\hline Alteração na Composição das Comunidades Íctias & 67 \\
\hline Invasão de Ambientes Artificiais por Insetos e Animais Silvestres & 67 \\
\hline Destruição de Sítios Arqueológicos & 67 \\
\hline Expectativa da População pela Geração de Empregos & 67 \\
\hline Atração de Migrantes & 67 \\
\hline Relocação de População: Urbana e/ou Rural & 67 \\
\hline Alterações no Microclima e na Qualidade do Ar & 67 \\
\hline Retenção de Sedimentos no Reservatório & 67 \\
\hline Interferência na Fauna Terrestre pela Redução de Habitats & 78 \\
\hline Sobrecarga na Infraestrutura Básica Local & 78 \\
\hline Ocorrência de Sismicidade Induzida & 78 \\
\hline Elevação das Receitas Públicas Municipais & 78 \\
\hline Interferência Sobre as Áreas de Situação Legal e Depósitos Minerais Conhecidos & 89 \\
\hline Revolvimento e Retirada da Camada Superficial dos Solos & 89 \\
\hline Relocação de Equipamentos Sócio-Culturais da Área Rural & 89 \\
\hline Alterações nas Condições das Águas & 100 \\
\hline Processos Erosivos & 100 \\
\hline Perda de Solos & 100 \\
\hline Deslizamentos & 100 \\
\hline Contaminação por Agentes Biológicos & 100 \\
\hline
\end{tabular}


Na tabela 3 é apresentada a frequência dos impactos na fase de operação das UHEs. Em apenas $10 \%$ dos documentos avaliados, impactos como poluição do aquífero, danificação de sítios arqueológicos e pressão sobre terras indígenas foram destacados como impactos negativos. Mais uma vez, é importante ressaltar a ocorrência destes impactos como dependentes a determinadas características do meio, como a existência de sítios arqueológicos ou terras indígenas.

Já alterações no microclima adjacente à obra e especulação imobiliária estão presentes em 80\% dos EIAs analisados sendo, portanto, considerados como impactos inerentes em usinas hidrelétricas.

Tabela 3- Frequência dos impactos observados na fase de operação dos EIAs.

\begin{tabular}{|c|c|}
\hline TIPO DE IMPACTO & $\%$ \\
\hline Poluição do Aquífero & 11 \\
\hline Dispersão de Sítios Arqueológicos e Erosão & 11 \\
\hline Pressão Sobre as Terras Indígenas & 11 \\
\hline Submersão dos Sítios Arqueológicos & 22 \\
\hline Interferência Sobre as Áreas de Situação Legal e Depósitos Minerais Conhecidos & 33 \\
\hline Elevação do Nível do Lençol Freático & 33 \\
\hline Criação de Novos Ambientes às Margens do Reservatório & 33 \\
\hline Alteração na Composição das Comunidades Íctias & 33 \\
\hline $\begin{array}{l}\text { Proliferação de Doenças Infecto-Contagiosas, Parasitárias e Avitaminoses e Acidentes com } \\
\text { Animais Peçonhentos }\end{array}$ & 33 \\
\hline Expectativa pela Desmobilização de Mão-De-Obra & 33 \\
\hline Alteração da Qualidade de Vida & 33 \\
\hline Perda de Memória Material Simbólica & 33 \\
\hline Conflito entre Empreendedor e População & 33 \\
\hline Interferência com Sistemas de Captação e Abastecimento & 33 \\
\hline Aumento da Oferta de Energia & 33 \\
\hline Possíveis Interferências Sobre Feições Cársticas/ Pseudocársticas no Patrimônio Espeleológico & 44 \\
\hline Estanqueidade do Reservatório & 44 \\
\hline Alteração do Sistema Viário & 44 \\
\hline Aumento da Ocorrência de Acidentes de Trabalho & 44 \\
\hline Sismicidade Induzida & 56 \\
\hline Contaminação dos Recursos Hídricos e Alteração na Qualidade das Águas & 56 \\
\hline Proliferação de Macrófitas Aquáticas & 56 \\
\hline Modificação das Relações Sociais e Culturais & 56 \\
\hline Instabilidade e Potencial Erosivo & 68 \\
\hline Alterações na Morfologia nas Calhas de Drenagem & 68 \\
\hline Interferências nas Comunidades da Fauna Terrestre para Redução de Habitats & 68 \\
\hline Atração de Migrantes & 68 \\
\hline Interferência nas Economias Urbanas & 68 \\
\hline Alteração nas Características da Paisagem & 68 \\
\hline Alteração na Qualidade dos Solos & 68 \\
\hline Alterações no Microclima na Qualidade do Ar & 79 \\
\hline Especulação Imobiliária & 79 \\
\hline
\end{tabular}

Durante a fase de operação, $70 \%$ dos documentos referentes às UHE, abordaram os seguintes impactos: instabilidade e potencial erosivo, alterações na morfologia das calhas de drenagem, interferência nas comunidades da fauna terrestre devido a alteração e redução dos hábitats, atração de migrantes, interferência nas economias urbanas, alterações nas características da paisagem e qualidade dos solos.

$\mathrm{Na}$ maior parte dos estudos analisados a insegurança da população em relação ao novo empreendimento na fase de planejamento é destacada. Isso se deve a grande modificação (tanto positiva quanto negativa) que uma obra de grande porte causa, tanto pela geração de emprego e renda, quanto pelo acréscimo de impactos socioambientais na região. Alguns estudos apontam ainda impactos mais específicos, como por exemplo, queda da produção leiteira e acidentes de trabalho e ocupacionais.

$\mathrm{Na}$ fase de implantação, os impactos observados são mais numerosos e recorrentes, já que nessa fase as intervenções começam, de fato, a serem executadas. Dessa forma, grande parte das alterações são observadas, 
essencialmente nos meios físico e biótico. As alterações no meio socioeconômico se dão, principalmente, pelo incremento no número de trabalhadores para a construção do empreendimento, sendo relatados, por alguns estudos, impactos negativos como aumento dos índices de prostituição, diminuição do interesse turístico pela região e realocação da população. Estes são impactos muito importantes e devem ser avaliados com bastante perícia, pois interferem diretamente na qualidade de vida da população local, refletindo-se no município e na região como um todo.

Na fase de operação, com a obra já concluída e grande parte da mão de obra desmobilizada, alguns estudos descrevem essa situação como o motivador de modificações na qualidade de vida da população, além de conflitos entre empreendedores e os empregados. É importante observar, que modificações positivas também são relacionadas em alguns estudos, como por exemplo, o aumento na oferta de energia e a valorização imobiliária no entorno do reservatório.

Todo e qualquer empreendimento deve ser avaliado na sua totalidade, considerando sempre tanto os impactos negativos, para que estes sejam corrigidos, evitados ou compensados de forma eficiente, como os impactos positivos, para que possam ser potencializados, trazendo benefícios a comunidade local.

A grande quantidade de impactos relatados em uma fase não a torna, necessariamente, a fase mais impactante do empreendimento. Isso porque a quantidade não reflete o poder de transformação dos impactos, ou seja, sua significância. Sendo assim, uma fase que tem um número menor de impactos pode ser a mais impactante, desde que estes apresentem os maiores níveis de significância.

A determinação da significância está associada a avaliação dos impactos, realizada concomitantemente a identificação e caracterização dos impactos. A partir da avaliação de impactos com estabelecimento dos graus de significância pode-se definir os programas ambientais, em especial, aqueles que devem ser implantados de forma prioritária, devido estarem relacionados aos impactos de maior grau de significância.

\section{Programas Ambientais Propostos}

Os programas ambientais e medidas mitigadoras e compensatórias utilizados para prevenir, mitigar ou compensar os impactos identificados na fase de planejamento das UHEs são apresentados na figura 3.

\begin{tabular}{|l|c|}
\hline $\begin{array}{l}\text { Fase do } \\
\text { Empreendimento }\end{array}$ & Programas e Medidas \\
\hline \multirow{5}{*}{ Planejamento } & $\begin{array}{r}\text {-Programa de Comunicação Social: Realização de oficinas, reuniões e palestras para a população / } \\
\text { Divulgação do empreendimento / Acompanhamento (assistentes sociais, antropólogos e } \\
\text { psicólogos) das famílias reassentadas e das comunidades afetadas / Realização de Audiência } \\
\text { Pública / Realização do Leilão de Energia / Compilação de uma base de dados ambiental de } \\
\text { uso público; } \\
\text { Erograma de Educação Ambiental: Elaboração do Estudo de Impacto Ambiental / Elaboração dos } \\
\text { Estudos de Viabilidade; } \\
\text {-Programa de Instalação de Infraestrutura Básica: Implantação do Escritório Local / Contratação } \\
\text { e Desmobilização de Mão de Obra; } \\
\text {-Programa de Remanejamento da População Diretamente Afetada: Procedimento de avaliação do } \\
\text { valor da terra a ser desapropriada }\end{array}$ \\
\cline { 2 - 3 } & $\begin{array}{c}\text { Programa de Estudo de Preservação e Revitalização do Patrimônio; } \\
\text { Programa de Desmatamento e Limpeza do Reservatório; } \\
\text { Programa de Resgate de Peixes nas Áreas Afetadas pelas Ensecadeiras. }\end{array}$ \\
\hline
\end{tabular}

Figura 3 - Programas e Medidas Ambientais da fase de Planejamento.

As medidas e programas ambientais exibidos no Quadro 2 foram comuns a todos os Estudos de Impacto Ambiental analisados. Referem-se basicamente a apresentação e divulgação do empreendimento à população.

Além destes, se verificou também alguns programas referentes a impactos ambientais das outras fases do empreendimento, como a implantação e operação, como é o caso dos programas de instalação de infraestrutura básica, de desmatamento e limpeza do reservatório e resgate de peixes nas áreas afetadas pelas ensecadeiras, verificando-se, portanto, um erro conceitual e de abordagem da equipe técnica que elaborou o EIA.

$\mathrm{Na}$ figura 4 podem ser observados os 
Programas e Medidas mais comuns propostos na fase de implantação das UHEs. Em primeira análise, verifica-se que os programas ambientais dessa fase são bem mais numerosos devido à alta diversidade de impactos encontrados na implantação de uma UHE.

Isso se deve as intervenções realizadas durante as obras que ocasionam uma modificação considerável no meio ambiente, tendendo a se estabilizar na fase de operação, como no caso das intervenções na flora, fauna e comunidade local. Sendo assim, um maior esforço é realizado para resolver os problemas sociais e ambientais encontrados

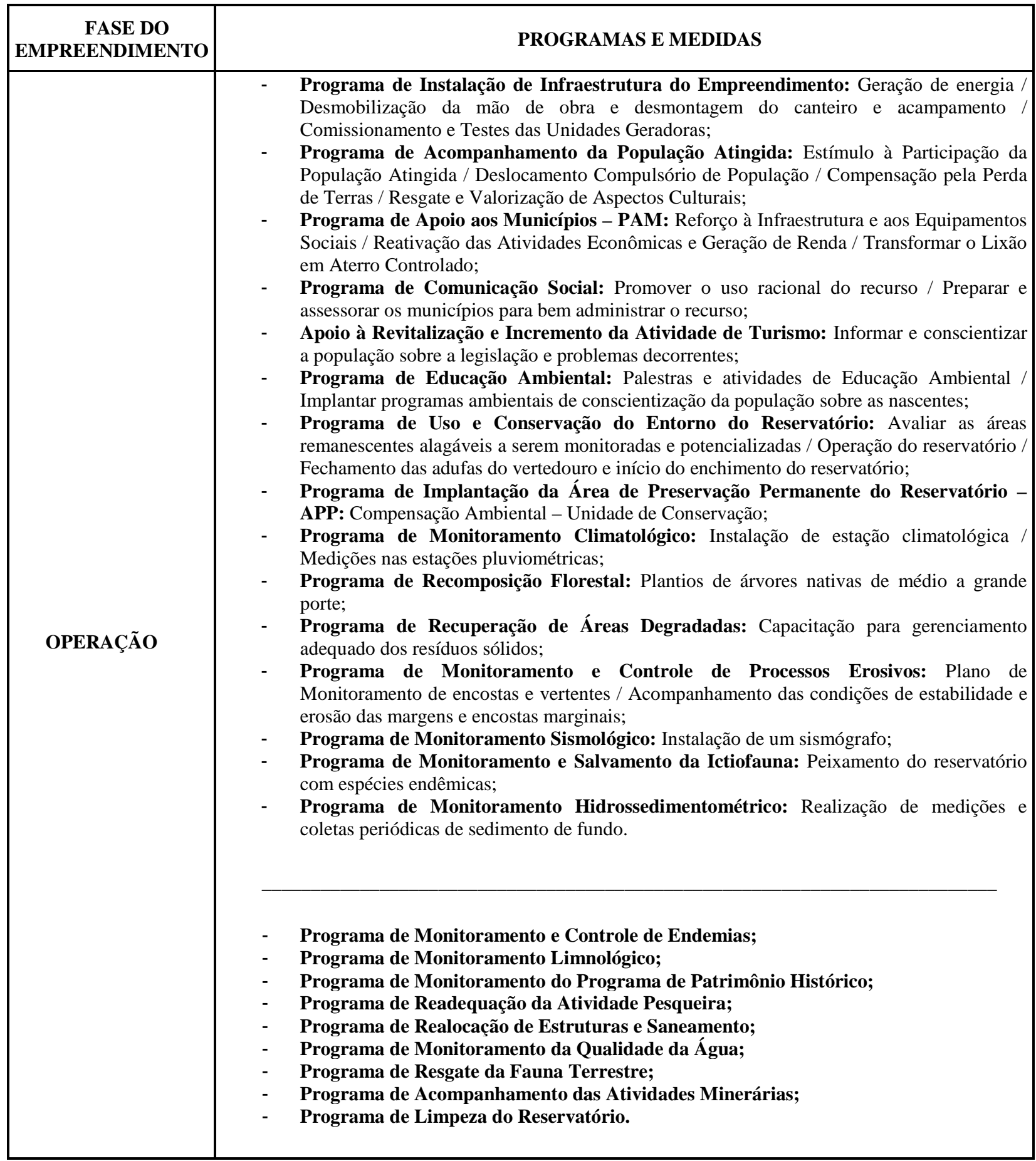

Figura 4 - Programas e Medidas Ambientais da fase de Implantação

Já os principais Programas e Medidas da fase de operação nas UHEs são exibidos na figura 5. Ressalta-se que na fase de operação as usinas hidrelétricas também apresentam uma grande quantidade de programas ambientais, devido a ser um empreendimento regional, que em geral afeta uma grande área devido a formação do reservatório, incluindo a necessidade de desapropriação, realocação de populações e da fauna, além da supressão de grandes áreas de 
vegetação nativa na maioria dos casos.

Os impactos ambientais negativos, gerados nas diferentes fases sejam estas planejamento, implantação e operação apresentados nas figuras 3, 4 e 5, respectivamente, sintetizaram os esforços dos empreendedores na tentativa de mitigação, controle e/ou compensação das modificações geradas no empreendimento.

\begin{tabular}{|c|c|}
\hline $\begin{array}{l}\text { Fase do } \\
\text { Empreendimento }\end{array}$ & Programas e Medidas \\
\hline \multirow[t]{2}{*}{ Operação } & 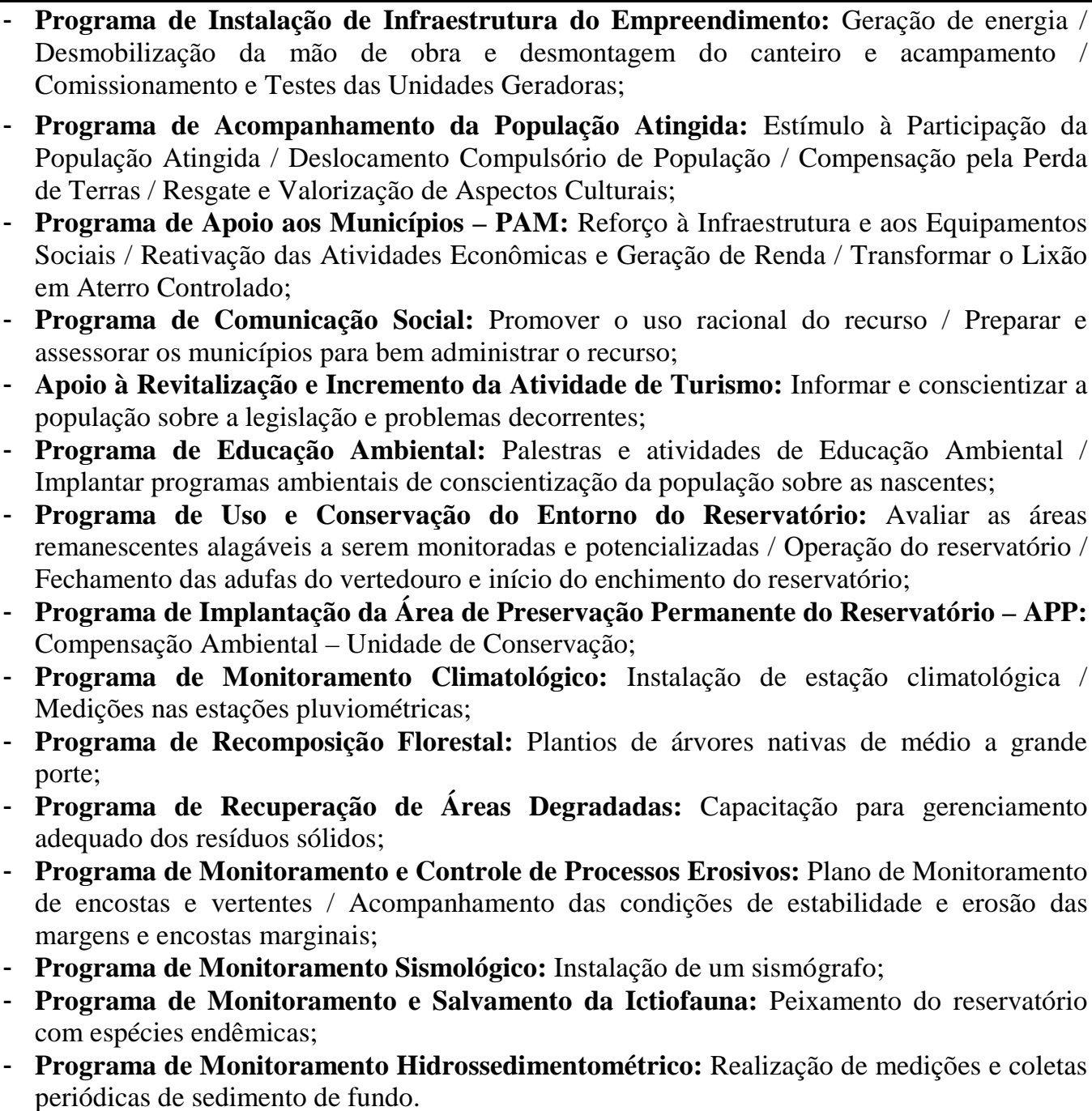 \\
\hline & $\begin{array}{l}\text { - Programa de Monitoramento e Controle de Endemias; } \\
\text { - Programa de Monitoramento Limnológico; } \\
\text { - Programa de Monitoramento do Programa de Patrimônio Histórico; } \\
\text { - Programa de Readequação da Atividade Pesqueira; } \\
\text { - Programa de Realocação de Estruturas e Saneamento; } \\
\text { - }\end{array}$ \\
\hline
\end{tabular}

Figura 5 - Programas e Medidas Ambientais da fase de Operação

Foi observado que na fase de planejamento, há relevante preocupação com os impactos relacionados ao meio socioeconômico, o que pode ser confirmado pela criação de programas de comunicação e interação social, nos quais são apresentados a população as características dos impactos que serão gerados, os prazos das ações a serem tomadas, dentre outras questões referentes ao empreendimento.

Já ao observar as peculiaridades dos programas e medidas apresentados para a fase de implantação, observa-se que em grande parte 
estes destinam-se a mitigar os impactos gerados pela modificação da infraestrutura local e promover acompanhamento das diversas atividades e processos da obra civil.

Nessa fase, procura-se ainda criar programas de compensação ambiental e de assistência a população diretamente afetada. Finalmente, na fase de operação, os programas e medidas envolvem atividades de acompanhamento dos programas ambientais já instalados nas outras fases, sendo o monitoramento e a gestão ambiental do empreendimento os instrumentos mais importantes para garantir a qualidade a longo prazo.

\section{CONCLUSÕES}

Por meio da análise comparativa realizada nos nove Estudos de Impacto Ambiental (EIAs) consultados, pode-se concluir que a padronização dos critérios para definição das áreas de influência é uma realidade nos casos em que os estudos são avaliados por um mesmo órgão ambiental, como foi o caso do presente trabalho. A tendência ainda é que a caracterização das áreas de influência seja feita com níveis cada vez maiores de detalhes, uma vez que se pôde verificar que estudos mais antigos eram bem menos exigentes que os estudos atuais, considerando aspectos mais gerais da área de implantação do empreendimento.

Contudo, verifica-se, ainda, erros conceituais e de abordagem em relação as definições de área de estudo e área de influência, além de não apresentarem os critérios utilizados para cada fator ambiental, focando somente $\mathrm{o}$ meio analisado.

Já com relação aos impactos e programas ambientais, estes tendem a variar de modo significativo de um empreendimento para outro, pois dependem, principalmente, das características do meio onde serão instalados.

Nota-se que os impactos menos frequentes foram aqueles que dependiam diretamente da existência de determinadas características do meio. De forma contrária, os mais comuns são aqueles ocasionados por atividades intrínsecas ao empreendimento, ou seja, independente do local ou do porte da instalação.

As questões de conflitos sociais causados pela desapropriação de terra, presença de população indígena ou comunidades que vivem segundo um modo de vida culturalmente ameaçado, caso das comunidades quilombolas, requerem atenção especial nos EIAs no sentido da preservação e manutenção de tais contextos sociais. Outro ponto fundamental nesse tipo empreendimento está relacionado ao manejo da fauna e flora afetadas diretamente pelo empreendimento, que necessitam de medidas compensatórias, na maioria dos casos associadas a unidades de conservação para realocação de determinadas espécies e a reposição da mata ciliar, atividades que são de longo prazo e necessitam da constituição de equipe técnica especializada em tempo integral. O processo de licenciamento e elaboração de EIA/RIMA é um mecanismo de controle ambiental que está evoluindo e tornando-se mais claro a cada dia. Houve um ganho em relação ao rigor adotado pelas agências licenciadoras nos processos, assim como na abrangência dos levantamentos realizados, conforme se pode observar na análise comparativa realizada nos EIAs. Mesmo com as melhorias notáveis ainda existem questões que causam polêmicas e dúvidas, o que é comum em se tratando de empreendimentos de grande porte que modificam intensamente e de forma irreversível a natureza e a comunidade em geral.

Haveria um ganho substancial na qualidade dos estudos e documentos elaborados se os órgãos ambientais estabelecessem critérios mais claros e objetivos para definição das áreas de estudo e de influência, e, principalmente, dos métodos de avaliação de impactos ambientais a serem usados, que ainda são muitos genéricos e qualitativos, pouco se utilizando de técnicas de simulação para definição de cenários.

Também nota-se um aumento gradativo da quantidade de informações gerada pelos EIAs, sem relação direta com a qualidade e confiabilidade da informação apresentada, já que muitos áreas do conhecimento ambiental dependem de um longo prazo, às vezes de décadas, para estabelecer realmente as interrelações entre os diferentes mecanismos e processos sociais, econômicos, físicos e bióticos. Em regiões que já possuem um histórico de pesquisas e estudos técnico-científicos a situação é minimizada, entretanto, destaca-se que o EIA se torna um instrumento mais confiável quando aplicado em conjunto com outros instrumentos 
ambientais, especialmente, o zoneamento ambiental e os planos de bacias hidrográficas, possibilitando que as informações apresentadas no EIA estejam inseridas dentro de um contexto de planejamento regional e não como um instrumento isolado de licenciamento.

Contudo, o licenciamento está se estruturando e se tornando mais forte e eficaz no seu papel de unir o desenvolvimento econômico, social e ambiental, de modo que se espera que daqui a alguns anos, todos os impasses e dúvidas hoje existentes sejam sanadas de maneira satisfatória e as tomadas de decisão possam ser feitas de forma mais confiável e com maior agilidade.

\section{REFERÊNCIAS}

ANEEL-Agência Nacional de Energia Elétrica. Matriz de Energia Elétrica. Atualizado em 15/05/2013. Disp. em: <http://www.aneel.gov.br/aplicacoes/capacidadebrasil/Operac aoCapacidadeBrasil.asp>. Acessado em 15/05/2013.

BORTOLETO, E.M. A implantação de grandes hidrelétricas: desenvolvimento, discurso e impactos. Geografares, Vitória, n. 2, jun. 2001.

BRASIL. Lei Federal $n^{\circ}$ 6.938, de 31 de agosto de 1981 . Dispõe sobre a Política Nacional do Meio Ambiente, seus fins e mecanismos de formulação e aplicação, e dá outras providências. Disp. em: < http://www.planalto.gov.br/ ccivil_03/leis/16938.htm>. Acessado em 19/01/2014.

BRASIL. Conselho Nacional de Meio Ambiente - CONAMA. Resolução $n^{0}$ 001, de 23 de janeiro de 1986. Disp. em: < http://www.mma.gov.br/port/conama/res/res86/res0186.html> . Acessado em: 19/01/2014.

BRASIL, Ministério de Minas e Energia. Plano Decenal de Expansão de Energia 2021. Brasília: MME/EPE, 2012.

BRASIL. Governo Federal. Disp. em: <http://www.brasil. gov.br/cop/panorama/o-que-o-brasil-esta-fazendo/matrizenergetica>. Acessado em 13/06/2012.

CEPEMAR-Centro de Pesquisa do Mar. Estudo de Impacto Ambiental do Campo de Jubarte. Capítulo 4, março de 2004.

CNEC ENGENHARIA S/A. Estudo de Impacto Ambiental da Usina Hidrelétrica de Estreito, 2001.

CNEC ENGENHARIA S/A. Estudo de Impacto Ambiental da Usina Hidrelétrica Tijuco Alto, 2004.

CHESF-Companhia Hidroelétrica do São Francisco. Estudo de Impacto Ambiental da Usina Hidrelétrica do Xingó, 1993.

COLITO, M.C.E. A construção de usinas hidrelétricas e os impactos sobre a população e o espaço. Serv. Soc. Rev., Londrina, v. 2, n. 2, p. 275 - 285, 2000.

CONAMA, Conselho Nacional do Meio Ambiente. Resolução $\mathbf{n}^{\mathbf{0}} 1$ de 23 de Janeiro de 1986. Disp. em: <http://www.mma.gov.br/port/conama/res/res86/res0186.html $>$ Acessado em 11/04/2012.

ECOLOGY BRASIL, Ecology and Environment do Brasil. Estudo de Impacto Ambiental da Usina Hidrelétrica do Santo Antônio do Jari, 2009.
ECOLOGY BRASIL, Ecology and Environment do Brasil. Estudo de Impacto Ambiental da Usina Hidrelétrica Itaocara, 2011.

EPE-Empresa de Pesquisa Energética. Estudo de Impacto Ambiental da Usina Hidrelétrica Teles Pires, 2007.

EPE-Empresa de Pesquisa Energética. Estudo de Impacto Ambiental da Usina Hidrelétrica São Manoel, 2008.

INEA-Instituto Estadual do Ambiente do Rio de Janeiro. Instrução técnica DECON $\mathbf{N}^{\mathbf{0}}$ 13/2008. Disp. em: $<$ http://urutau.proderj.rj.gov.br/inea_imagens/downloads/it/IT _DECON_2008-13.pdf > Acessado em 16/ 06/ 2012.

LELI, I.T.; ZAPAROLI, F.C.M.; SANTOS, V.C DOS; OLIVEIRA, M.; REIS, F.A.G.V. Estudos ambientais para cemitérios: indicadores, áreas de influência e impactos ambientais. Revista Boletim de Geografia, Maringá, v. 30, n. 1, p.45-54. 2012.

OLIVEIRA, A. \& ZHOURI, R. Desenvolvimento, conflitos sociais e violência no Brasil- rural: o caso das usinas hidrelétricas. Ambiente \& Sociedade, Campinas, v. X, n. 2, p. 119-135, 2007.

PROJETEC-PROJETOS TÉCNICOS LTDA; CNECEngenharia S/A. Estudo de Impacto AmbientalEIA/Aproveitamento Hidroelétrico Uruçui, Rio Parnaíba, 2009a.

PROJETEC-PROJETOS TÉCNICOS LTDA; CNEC Engenharia S/A. Estudo de Impacto AmbientalEIA/Aproveitamento Hidroelétrico Cachoeira, Rio Parnaíba, 2009b.

SÁNCHEZ, L.E. Avaliação de Impacto Ambiental: conceitos e métodos. São Paulo: Oficina de textos, 495p. - 2006.

SANTOS, R.F. Planejamento Ambiental: teoria e prática. São Paulo: Oficina de textos, 184p. 2004.

THOMPSON, M.A. Determining Impact Significance in EIA: a Review of 24 Methodologies. Journal of Environmental Management. v. 30, p. 235-250, 1990.

Submetido em 23 de agosto de 2015 Aceito em 6 de março de 2018 